\title{
The Design of Color Detector Device for Visually Impaired People
}

\author{
Mochamad Bintang Rivani ${ }^{1}$, Kristiana Asih Damayanti ${ }^{2, *}$ and Ali Sadiyoko ${ }^{3}$ \\ ${ }^{1}$ Industrial Engineering Department, Faculty of Industrial Technology, Parahyangan Catholic University \\ Jalan Ciumbuleuit 94 (Bandung, Indonesia) \\ ${ }^{2}$ Industrial Engineering Department, Faculty of Industrial Technology, Parahyangan Catholic University \\ Jalan Ciumbuleuit 94 (Bandung, Indonesia) \\ ${ }^{3}$ Industrial Engineering Department, Faculty of Industrial Technology, Parahyangan Catholic University \\ Jalan Ciumbuleuit 94 (Bandung, Indonesia) \\ *Corresponding author's email: krist [AT] unpar.ac.id
}

\begin{abstract}
This study was conducted to create a design of color detector device that can meet the needs of people with visual impairments. In the early stages of research, interviews was held to determine the difficulties that were being faced by the visually impaired when identifying color difference. Further interviews were conducted in order to obtain their further needs to the design of a color detector device. The next thing to do was to determine the importance rating of each need that was identified. Based on the importance rating of the needs, some design concepts were generated by using some combination tables. Three design concepts are generated and concept selection was conducted by involving users and external designer. Anthropometric data was used for determining the dimensions of the selected design. The device that was designed was a color detector device with a voice output. To gain a real feedbacks from users, final prototype was then made for testing both of its function and design. A variety of electronic components, including color sensor, microcontroller, chip recorder, and speaker were used to test the function of color detector device. Meanwhile, a case design was produced by using $3 D$ printer technology with ABS plastic materials. Based on the final prototype, a test was held to obtain the user's response on its function and design. The test results several feedbacks for future development of the product including a lighter weight, smaller size, louder voice output, more accurate color defining, and wider range of object source selection for color identification.
\end{abstract}

Keywords— Product Design, Visually Impaired People, Color Detector

\section{INTRODUCTION}

The number of blind people has reached a high figure nowadays. World Health Organization (WHO) stated 285 million people worldwide has a decreased visual ability (visual impairments). Nearly 39 million people of them are having a total blind condition, while the other 246 million people are having a low vision condition [1]. General Directorate of Social Rehabilitation of Indonesia under the Ministry of Social Affairs of Republic Indonesia stated that in 2020, the number of visually impaired people is going to be increased by two times (Djunaedi, 2010).

Given this fact, the Indonesian government is currently undertaking rehabilitation to the blind people, so that they could live independently without relying on others. This approach is being taken in order to increase their standard of living so that they can be more productive. PSBN Wyata Guna is one of the technical unit in the field of rehabilitation and social services that located in Bandung, Indonesia. It is hard for the visually impaired people who live in Indonesia to live independently. The reason behind this is because the facilities that are available to help the daily activities of visually impaired people are still fairly minimal.

Currently, the visually impaired people in Indonesia have been being helped by several products. Based on a survey conducted by WHO Indonesia [2], there are at least 5 types of visual-aid products are listed on the study, including eye glasses, magnifying devices, tactile sticks, Braille writer tools, and spoken devices (such as: calculator and hand watch). However, up until this day, they are still facing some difficulties in performing daily routine activities. In order to make them live independently, it is required to develop some products that is specifically designed to support their activities. Product design and development for special population, i.e. visually impaired people, may help them reach a higher standard of living.

In doing this research, the visually impaired people that lives at PSBN Wyata Guna Bandung are being sampled as respondents. Based on interview that is conducted in the early stage of the research, they faced a difficulty in 
distinguishing color, for example when one of the respondents, Deden (29 years old), is going to select some clothes then he will distinguish it only by its physical features, such as: the position of the pockets, the sleekness of its materials, or the size of its buttons. In order to know the color of his clothes, he will ask his friend the color of his clothes. As an alternative solution to this problem, a color detector device is needed to help them. A research that is focused on designing a color detector device with voice output is then conducted to support them to live independently. The proposed design of this study can be produced to solve problem of color identification for the visually impaired people.

\section{METHODS}

The design was conducted first by interview to identified need of the device that really need by impaired people. Background study was also conducted to support the research. The concepts developed to answer the needs. Concept selection was done to select the proper and right concept to develop. Concept testing was conducted by the sample of user. Figure 1 shows the methodology that is applied in conducting this research. In generating the product concept design, A Front-End Process [3] development phase was adapted from mission statement to testing product concept as shown in Figure 2.

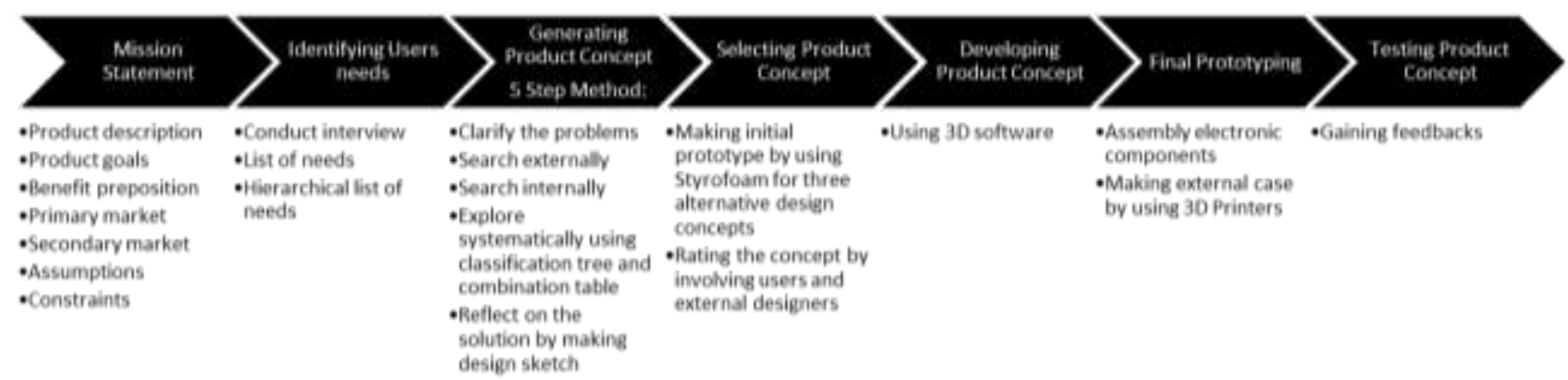

Figure 1 A Front-End Process Development Phase Methodology (Adapted from Ulrich \& Eppinger [3])

\section{RESULTS}

At first, a mission statement is generated as shown in Table 1 based on product design and development. Data were collected by interviewing respondents who live in PSBN Wyata Guna. There are 8 respondents who involved in this study with age range in $20-56$ years old. The interview was conducted to collect data of needs, in these interviews we got qualitative data that is interpreted it into list of needs. Level of interests are given to each list of needs by using tally of frequencies and comprehensive analysis. Table 2 shows the level of interests for each identified needs.

Table 1 Mission Statement

\begin{tabular}{|l|l|}
\hline \multirow{2}{*}{ Product Description } & $\begin{array}{l}\text { Color detector device that may help visually impaired people in } \\
\text { identifying color }\end{array}$ \\
\hline \multirow{2}{*}{ Product Goals } & $\begin{array}{l}\text { Helping users, especially visually impaired people in identifying } \\
\text { color }\end{array}$ \\
\hline \multirow{2}{*}{ Benefit Preposition } & Easy and comfortable device \\
\cline { 2 - 2 } Primary Market & Able to identify 16 different color \\
\hline \multirow{2}{*}{ Secondary Market } & Visually impaired people in Indonesia \\
\cline { 2 - 2 } Assumptions & Public society \\
\hline \multirow{2}{*}{ Constraints } & $\begin{array}{l}\text { No significant technological development during product } \\
\text { development }\end{array}$ \\
\hline & $\begin{array}{l}\text { The research was conducted solely at PSBN Wyata Guna Bandung, } \\
\text { Indonesia }\end{array}$ \\
\cline { 2 - 2 } & The design is suited with existing technology in the market \\
\hline
\end{tabular}


Table 2 Level of Interest (Hierarchical List of Needs)

\begin{tabular}{|c|l|l|}
\hline Number & \multicolumn{2}{|c|}{ Device shapes } \\
\hline 1 & $* * *$ & A small size device \\
\hline 2 & $* * *$ & A lightweight device \\
\hline 3 & $* * *$ & A comfortable device \\
\hline 4 & $*$ & A device that is attached to eyeglasses \\
\hline & \multicolumn{2}{|c|}{ Device features } \\
\hline 5 & $* * *$ & A device that can tell colors \\
\hline 6 & $* * *$ & A device that can be used individually \\
\hline 7 & $* *$ & A device that may distinguish money \\
\hline 8 & $* *$ & A device with voice output in Bahasa Indonesia \\
\hline 9 & $* *$ & A device that can be used to various objects \\
\hline 10 & $* *$ & A device with affordable price \\
\hline 11 & $*$ & A simple mechanism device \\
\hline 12 & $*$ & A rechargeable device \\
\hline 13 & $*$ & A multifunction device \\
\hline 14 & $*$ & A device that can detect barrier \\
\hline
\end{tabular}

Description :

$(* * *)$ Very Important; (**) Fairly Important; (*) Less Important

After generating mission statement and list of needs with levels of interests from users, the next stage is designing product concept. Several steps were performed in order to make a product concept, i.e. product problem explanations, external and internal searching, and explorations process. Product problem explanations are presented in a function diagram which consists of input and output of the color detector device. Figure 2 presents a basic function diagram.

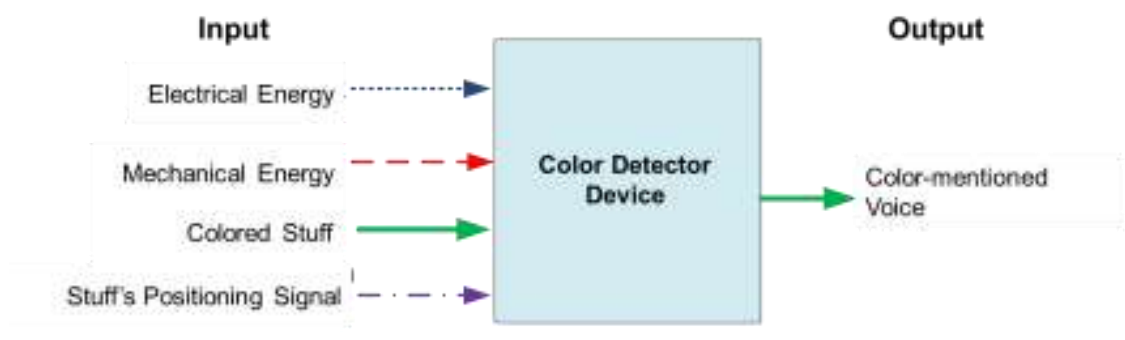

Figure 2 Basic Function Diagram

Furthermore, a decomposition of function diagram is then performed. As a result, seven integrated sub functions are gained in order to make a system of the color detector device. Those seven sub functions are as follows:

1. Electricity energy receipt from battery

2. Device positioning

3. ON/OFF button suppresion

4. Color sensor activation

5. Objects color information collection

6. Matching process between color information and microcontroller database

7. Use of speaker as output 
Input

Output

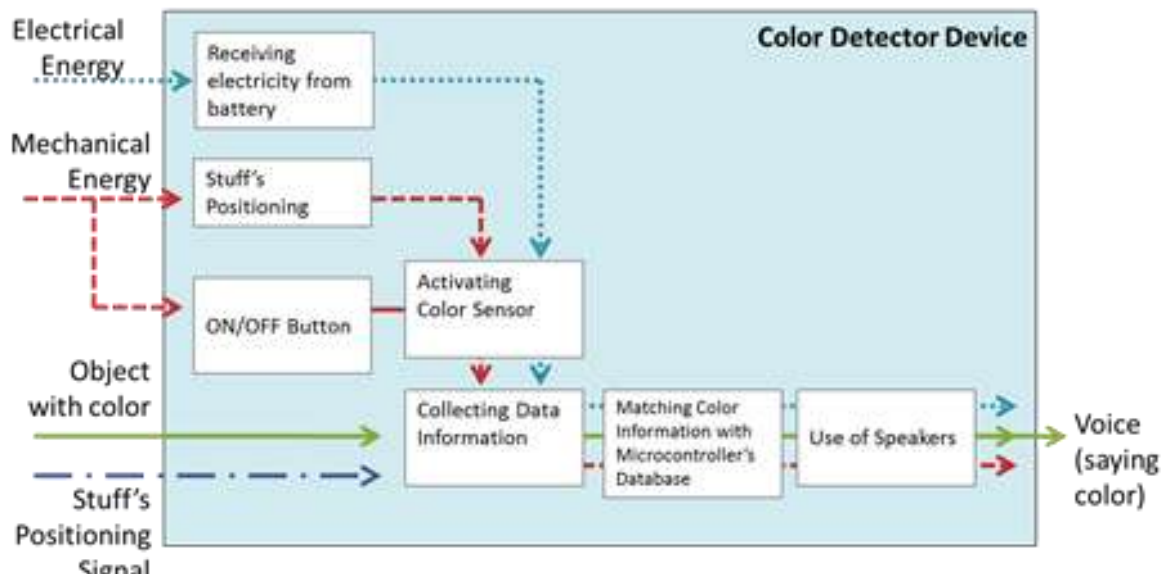

Figure 3 Decomposition of Function Diagram

From each sub functions mentioned above, several alternative solutions are ideated in order to solve problems. Ideation are performed by searching both internally and externally through some creative processes such as sketching, mind mapping, and collage making. Figure 4 describe the process of brainstorming to create design concepts.

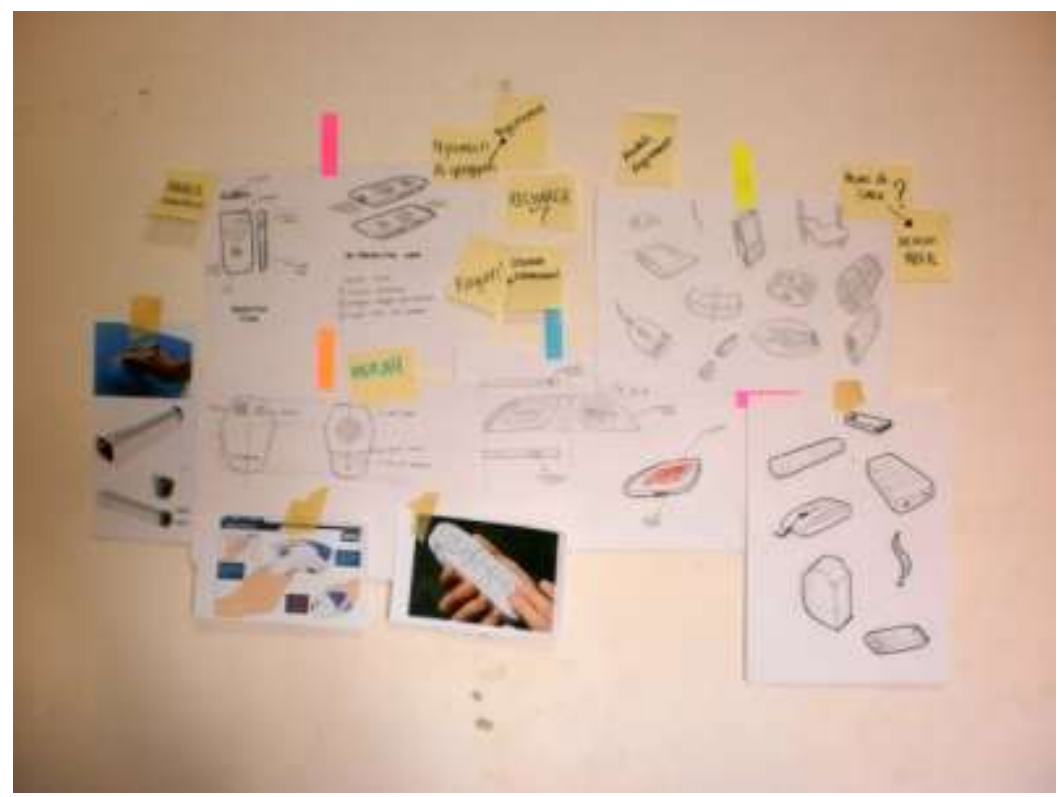

Figure 4 Brainstorming Result

Exploration process are then conducted to filter and refine the alternative solutions into three solutions. The sketch of those three design concepts can be shown in Figure 5.

Based on those three alternative design concepts, a selection is arranged to choose the best idea. The selection process is involving 4 respondents, three of them are the visually impaired people while the other one is a designer. This selection process is not only supported by sketches of design concepts but also by making initial prototypes (mock-up design) as shown in Figure 6. These mock-up designs are made in order to make a real experience of the design concepts so that can make respondents easier to decide which concept is better based on their own perspectives. There are three categories that are being assessed: functionality, comfort aspect, and ergonomic aspect. Table 3 shows the result of the selection process presented in average. 

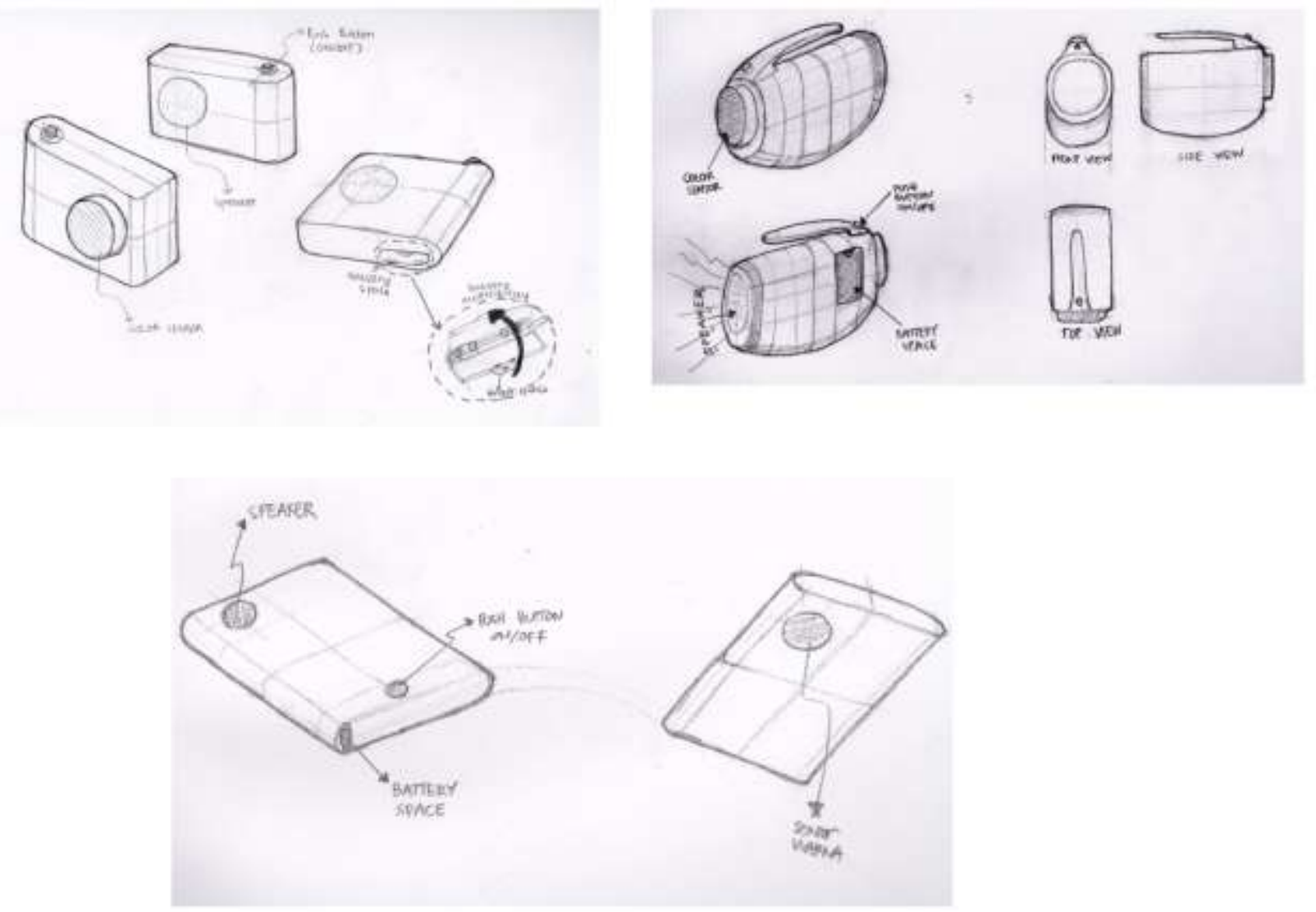

Figure 5 Design Concepts

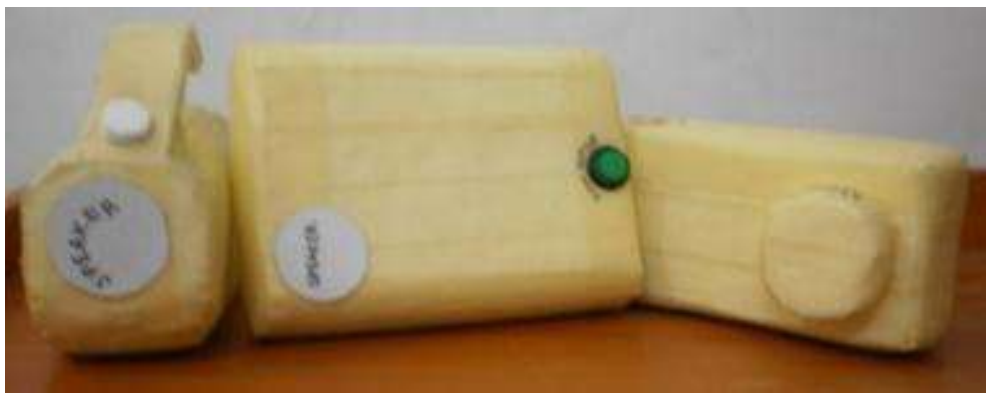

Figure 6 Initial Prototypes

Table 3 Average of the Selection Process

\begin{tabular}{|l|c|c|c|}
\hline & Average & Ranking & Proceed? \\
\hline Concept 1 & 3,25 & 1 & Yes \\
\hline Concept 3 & 2,25 & 2 & Develop \\
\hline Concept 2 & 0 & 3 & No \\
\hline
\end{tabular}

Based on the selection process, design concept number 2 will not be proceed, since the average value is fairly minimal. Meanwhile, design concept number 1 and 3 will be developed, resulting a refinement that can be shown in a 3D view in Figure 7. The 3D is made by using AutoCAD software.

The next stage of this research is making a final protoype. The prototype is a high-fidelity prototype. This stage is then divided into two sections: electronic components assembly, and the making of external case. Microcontroller, Chip Recorder, Speaker, and Color Sensor are some electronic components that are being used in this research based on another research conducted by Okta Setia Pratama in 2012 [5]. 
The electronic components assembly process are based on function diagram that is generated previously. The result of this assembly process can be shown in Figure 8. Another section is the making of external case by using 3D printer. ABS plastic is the material that is used in this process as shown in Figure 9.
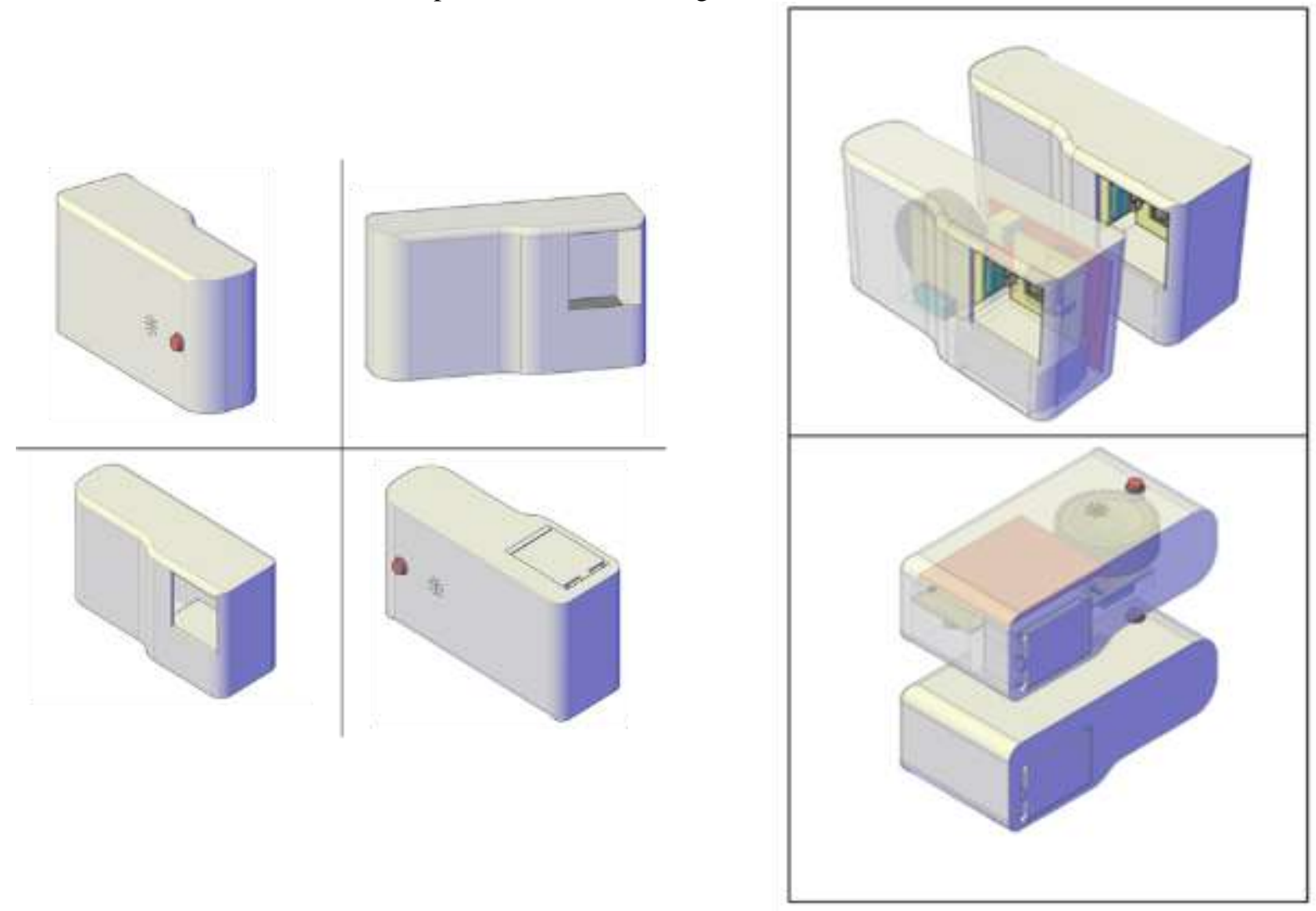

Figure 7 3D Design Concept

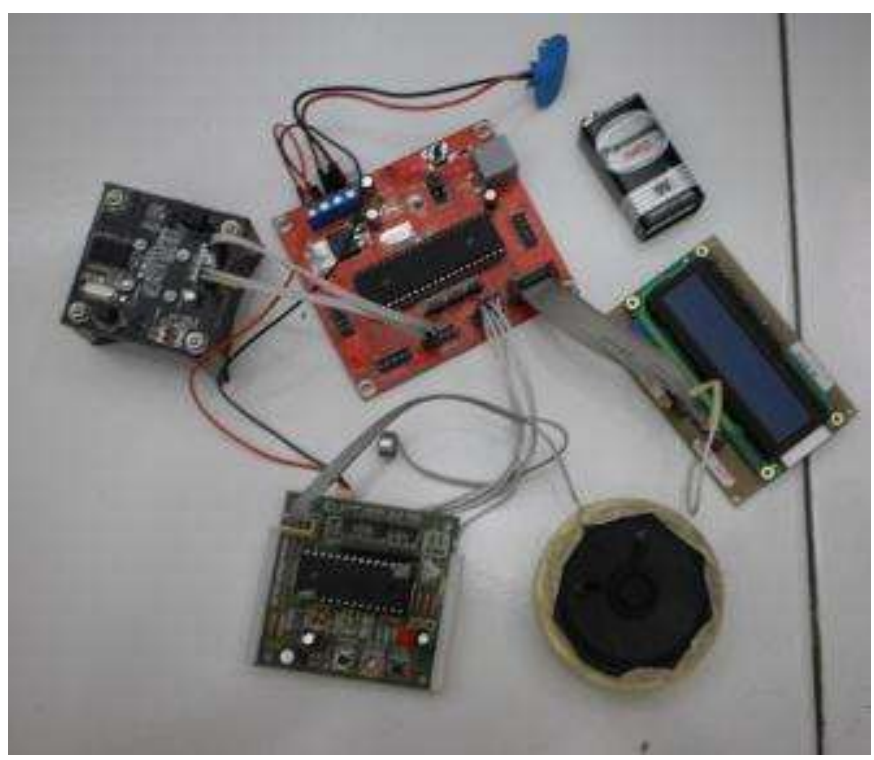

Figure 8 Final Assembly of Electronic Components 


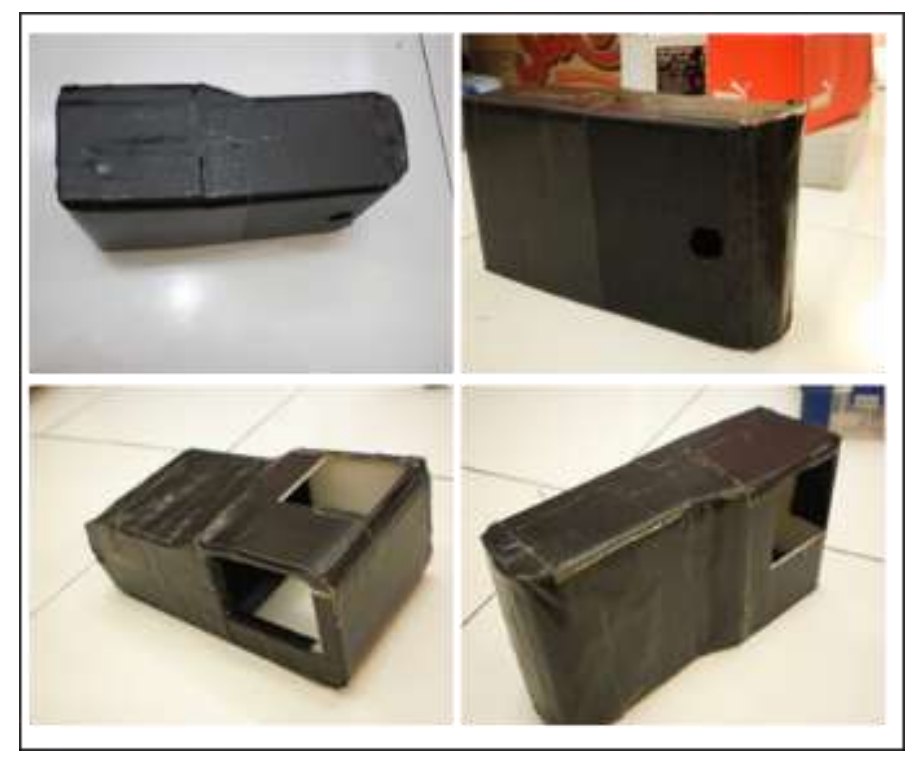

Figure 9 Final Assembly of External Case (using 3D Printers with ABS Plastic Material)

Moreover, a test is conducted in order to evaluate the final prototype. The test is performed by gathering qualitative data through interview (collecting both positive and negative comments on the final prototype). The testing process is divided into two sections: shape testing and device function testing. Table 4 and Table 5 are both shows the result of the final prototype.

Table 4 Qualitative Data - Shape Testing

\begin{tabular}{|l|l|}
\hline \multicolumn{2}{|c|}{ Comments } \\
\hline \multicolumn{1}{|c|}{ Positive } & \multicolumn{1}{c|}{ Negative } \\
\hline Easy to use & The size is too big \\
\hline Fairly comfort to use & Heavy \\
\hline
\end{tabular}

Table 5 Qualitative Data - Functionality Testing

\begin{tabular}{|l|l|}
\hline \multicolumn{1}{|c|}{ Positive } & \multicolumn{1}{|c|}{ Negative } \\
\hline Using Bahasa Indonesia & Color defining is fairly accurate \\
\hline & The output voice is low \\
\hline & $\begin{array}{l}\text { Still can't accommodate the color } \\
\text { identification of several objects }\end{array}$ \\
\hline
\end{tabular}

\section{CONCLUSION AND SUGGESTIONS}

The color detection which was design can be used to detect several color in specific range, so it need to develop the device to detect more range, also need develop to redesign smaller and compact casing for the device. For the first negative comments regarding shape testing is "The size is too big", this is the effect of the constraints stated on the mission statement (Table 1) that says "The design is suited with existing technology in the market". As the future development of the product, its dimension should be based on the Anthropometric data of Indonesians users as shown on Table 6 below. The proposed revised 3D design by adapting the anthropometric data can be seen on Figure 10 .

Table 6 Anthropometric Data of Indonesian Users (centimeters)

\begin{tabular}{|c|c|c|c|c|c|c|c|c|}
\hline \multirow{2}{*}{ Dimension } & \multicolumn{4}{|c|}{ Male Citizens } & \multicolumn{4}{c|}{ Female Citizens } \\
\cline { 2 - 11 } & P5 & P50 & P95 & SD & P5 & P50 & P95 & SD \\
\hline Hand Length & 17 & 19 & 22 & 1.64 & 16 & 18 & 20 & 1.72 \\
\hline Hand Breadth & 7 & 9 & 11 & 1.09 & 6 & 8 & 10 & 4.85 \\
\hline
\end{tabular}




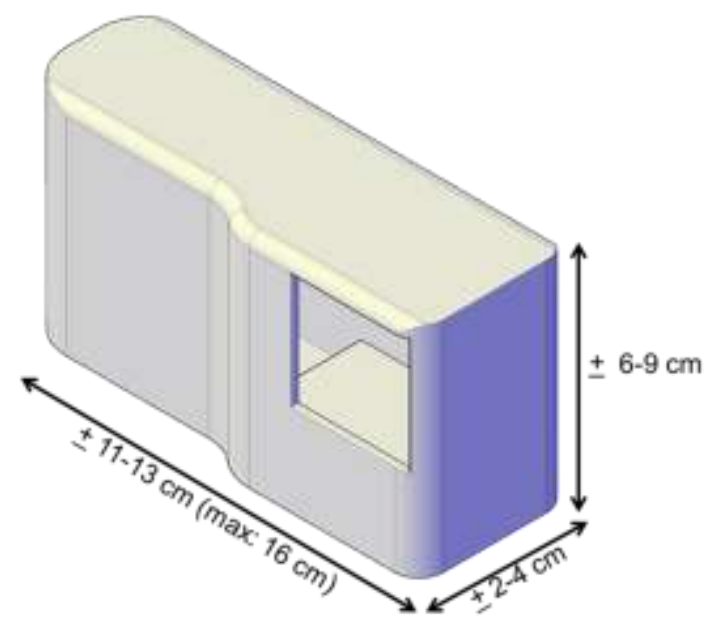

Figure 10 Revised 3D Design (Product Dimension using Anthropometric Data)

The second negative comments regarding shape testing is "Heavy", this is the effect of using ABS plastic materials. 3D printer technology make it possible to make a quick and accurate prototype design, however the materials that are being used should be considered. ABS Plastic materials is quite heavy that results 100 grams of total weight of the final prototype. For better future development, the chosen materials should be considered another kind of plastic with lighter weight.

Meanwhile, on the functionality testing there are at least three negative feedbacks. The first negative feedbacks is in terms of the accuracy of color defining. This can be improved by developing the algorithms used in the microcontroller. In this study, the RGB scale are being used in order to present the final prototype. Algorithms by using RGB is fairly accurate since the grouping of color is based on its primary color.

The second negative feedbacks is regarding its low output in speakers. This may be improved by adding another type of speakers. The third negative feedbacks is regarding its limitation in identification of several objects. The device is using color sensor with light function which may not reflect an accurate result if the objects are highly reflecting the lights. This may be improved by replacing the type of the color sensor.

For further development of the products, some suggestions that can be gained from this study are:

1. The study should involve a wide range of respondents including those who live independently in their home to define a more accurate problems.

2. The study should consider financial aspects, so that the products that are being developed can be produced in a large scale to help more visually impaired people

3. The study should involve current trends of technology to improve the function and design.

\section{REFERENCES}

[1] Mariotti, Silvio P., "Global Data on Visual Impairments 2010”, World Health Organization (WHO), 2010.

[2] Khasnabis, Chapal, "Daftar Produk Alat Bantu Prioritas (APL)", World Health Organization (WHO) Indonesia, 2015. http://www.who.int/phi/implementation/assistive_technology/indonesian_apl_global_survey_for_web.pdf

[3] Ulrich, K.T., Eppinger, S.D. "Product Design and Development 4th ed.", New York: McGraw Hill, US, 2008.

[4] Kroemer K., Kroemer H., Kroemer-Elbert K., (2001). Ergonomics: How to Design for Ease and Efficiency 2nd ed. New Jersey: Prentice Hall.

[5] Pratama, Okta Setia, "Pengenal 16 Warna Dasar untuk Buta Warna dengan Output Suara" Surabaya: Institut Teknologi Sepuluh Nopember. 2012

[6] Deborah L. Pfeiffer, Ed.D. "Guidelines for Working With Students Who Are Blind or Visually Impaired In Virginia Public Schools." Virginia: Virginia Department of Education, Office of Special Education and Student Services, 2010.

[7] Sutalaksana I.Z., Anggawisastra .R, Tjakraatmadja J.H. (1979). Teknik Tata Cara Kerja. Bandung: Institut Teknologi Bandung. 